\title{
ASSESSMENT OF LOW DISEASE ACTIVITY STATUS IN PATIENTS WITH SYSTEMIC LUPUS ERYTHEMATOSUS IN A TERTIARY HOSPITAL IN SÃO PAULO, SP.
}

Barbara Luzia Berredo Reis Alexandre1, ${ }^{1, \star}$, Marina de Azevedo Martins ${ }^{1}$, Lucas Guimarães Nolasco Farias ${ }^{1}$, Marcelo Antônio Carreira Cavalcanti de Albuquerque Filho' ${ }^{1}$, Deivid Souza Sutti Lopes ${ }^{1}$, Paula de Medeiros Nacácio e Silva ${ }^{1}$, Nathália de Carvalho Sacilotto ${ }^{1}$, Renata Ferreira Rosa ${ }^{1}$, Rina Dalva Neubarth Giorgi ${ }^{1}$, Nafice Costa Araújo ${ }^{1}$

1.Instituto de Assistência Médica ao Servidor Público Estadual, São Paulo (SP), Brazil.

*Corresponding author: barbara_berredo@hotmail.com

\section{BACKGROUND}

Systemic lupus erythematosus (SLE) is a chronic autoimmune disease that affects multiple organs and generates a significant impact on the individual's quality of life. The recurrent pattern of the disease is associated with greater damage. Several metrics have been developed to measure the state of low-activity lupus disease and/or remission. Lupus low disease activity state (LLDAS) was associated with reduced damage and mortality in SLE. The objective of this study was to characterize the clinical and epidemiological profile of patients with SLE and classify them according to the state of low disease activity in a tertiary hospital using the LLDAS.

\section{METHODS}

This is a cross-sectional study, which evaluated 241 patients with SLE aged $\geq 18$ years, according to the ACR 197 and/or the SLICC/ACR 2012 criteria, actively followed up in the SLE outpatient clinic, from July 2020 to July of 2021. The consultation was performed through electronic medical records, where demographic data, SLE classification criteria, medication use, physician's global assessment (PGA) and disease activity (SLEDAI-2K) were selected at the time of the last consultation with the doctor. These data allowed us to define the patients who achieved the LLDAS.

\section{RESULTS}

The mean age of patients was 52.92 years, $95.87 \%$ were female and the mean disease duration was 13.72 years. The most frequent clinical criteria were articular (74.75\%) and cutaneous (72.60\%); $91.29 \%$ had positive ANA. The medications currently in use were: hydroxychloroquine (75.9\%), mycophenolate mofetil (15.76\%), methotrexate (9.64\%), azathioprine (7.46\%), prednisone $>7.5 \mathrm{mg} /$ day (5.8\%), rituximab (3.31\%), belimumab (2.07\%), cyclophosphamide $(1.24 \%$ ) and tacrolimus $(1.24 \%) ; 77.15 \%$ of patients were not using prednisone; $98 \%$ of patients had $2 \mathrm{~K} \mathrm{SLEDAI} \leq 4$ and $74.68 \%$ of patients met LLDAS criteria. Among those who did not meet all LLDAS criteria, $7 \%$ had new activity compared to the previous visit, $11 \%$ with PGA $>1,7 \%$ with prednisone dose $>7.5 \mathrm{mg} /$ day, $17 \%$ needed to change the immunosuppressant dose and $2 \%$ with SLEDAI $2 \mathrm{~K}>4$.

\section{CONCLUSION}

Our registry shows that most of our lupus patients are in a state of low disease activity, through the LLDAS, with less than $1 / 3$ using prednisone. This favorable result highlights the importance of using a therapeutic arsenal that helps control the disease and saves the use of corticosteroids, as well as assessment tools in routine consultations.

\section{KEYWORDS}

Systemic lupus erythematosus, LLDAS, SLEDAI 2k. 